\title{
Research on Public Service Equalization of Chinese Urban and Rural Basic Education under Financial Perspective
}

\author{
Zhengwang $\mathrm{Li}^{1}$, Xiayang $\mathrm{Liu}^{2}$ \\ ${ }^{1}$ Wuhan Textile University, Wuhan, Hubei, 430000 \\ 346591653@163.com
}

KEYWORDS: Finance; Urban and Rural; Basic Education; Equalization of Public Services

\begin{abstract}
Since the reform and opening up, Chinese policy support for rural has gradually increased in the process of rapid economic development, however, multifaceted, multi-angle gap still remains between the urban and rural public services specific to basic education between urban and rural areas, this paper introduces basic public education from the perspective of financial analysis of rural and urban basic education for reasons of public service differentiation, combined with practical problems to mention concrete measures, further theory researchers, policy makers and gradually improve policies has a certain significance.
\end{abstract}

\section{Introduction}

Party Fourth Plenary Session eighth made it clear implementation of urban and rural equalization of basic public services is the question of the future of the party and the government should focus on building urban and rural areas to improve basic public services system has a theoretical and practical significance, and urban and rural public service equalization of basic education is the build a sound basic education in urban and rural public service system, there is an important link. Therefore, this aspect of the financial system in theory has a positive role in promoting sound; on the other hand, a systematic study is conducive to better implement in practice of urban and rural basic education equalization of public services, and gradually narrow the differences between urban and rural areas in the supply of public services gap.

\section{Financial Elements Troubled Urban and Rural Public Service Equalization}

(A) Financial excessive level

China's implementation of the five government regulatory system, therefore gradually formed five financial approval system, excessive levels of financial distress brought not only to the central, but also bring about the difficulty for the implementation of local finance. Intermediate links, the more low financial efficiency, the implementation of basic education to local public services policy is to implement the scheme in a real lack of effectiveness. Therefore, excessive fiscal hierarchy is China's basic education urban and rural public service equalization is a major key factors.

The implementation of the tax system since 1994, the central and local financial authority and powers exist large differences in the distribution of central financial power concentrated, miscellaneous local powers, making the financial system functioning five layers bottleneck occurs, the central funding there is often delegated to reach places lag and other problems for sustained economic development has brought problems. Meanwhile, in the five fiscal practice, the approval 
procedures, reporting and disbursement of part of links there are problems to keep up with the progress of the project, so that the effect of urban and rural infrastructure to implement basic education in public services compromised. More specific differences between urban and rural areas, urban infrastructure through the implementation of tertiary education finance public services, and to reach the town you need to go through all the five Finance, which is the reason for the lag in the implementation of township issues on the basis of education where public services.

(B) Lack of grass-roots financial self-sufficiency

At present, China has adopted five fiscal operation system, local and central financial capacity far, we can say, "Xinyou, power shortage," For a long time, our public service to implement differentiated cost sharing, public services, urban basic education indirectly purchased by the residents costs are more concentrated in tax revenue, the other hand in rural areas, whether it is before or after the reform and opening up the reform and opening up, financial support mechanism to ensure that farmers can not afford the synchronization of the city.

Since the founding, remove foreign financial subsidies received from superiors, the remaining revenue mainly rely on fee income, resulting in long-term presence in rural areas of arbitrary charges after another; from the reform and opening up to the present day, the city's public services, basic education that can raise revenue main source of income tax revenue and other specifications, to some extent, local governments have the ability to achieve self-arrange the construction of basic education and investment in public services. But the other hand, rural grassroots finance in recent years, rapid real estate development, finance grassroots in order to maintain normal operation, and is attracting interest, have been willing to risk fought in real estate, one time land and residence in rural areas and fired hot, revenue is short-term It realized, but in the long run, this approach is tantamount to self-harm than break retreat. Built up on the basis of basic education public service system also vulnerable, urban and rural financial supply gap still exists.

(C) The expenditure is not obvious

Expenditure not a simple appropriation, specific whereabouts expenditure of funds how, if there is follow-up measures, how to use efficiency are the key to improve expenditure system. With annual revenue growth, fiscal spending is also appropriate scale, particularly to rural and urban basic education equalization of public services, the expenditure part of the township financial regulation exists does not in place and the financial body problem, did not achieve the desired result in expenditure effect, so spent the money but did not get things done in the situation greatly affected the financial position of public service in the construction of basic education, but also of urban and rural public service equalization of basic education is a major factor.

One of the key causes of ineffective expenditure, there is no uniform definition and allocation of expenditure on public services for basic education, were dispersed to various fields, industries, but there is no centralized management mechanism, therefore, expenditure to put in the presence of a certain percentage of specific projects on the basis of education in the public service utilization loss, financial resources cannot be promoted.

\section{The Financial Methods to Promote Urban and Rural Public Service Equalization of Basic Education}

Range sound fiscal regime involves a wide range, specific to the rural and urban basic education public service equalization of fiscal measures, the Chinese government can change and efforts in the following aspects. As the International Experience section of the essential configuration of the central and local financial authority; in addition, the transfer payment system reform, our unique structural change and the construction of basic education in financial binary public services are in 
financial system reform Specific details, only to reform the system, in order to promote urban and rural elementary education a fundamental public service equalization.

(A) Financial Power Allocation balance between central and local

Chinese financial system has been running for 21 years. The property rights and the division of power between central and local governments and confirm it gradually blurred, so reducing the efficiency of the system based on vertical fiscal transfer payment. Grasp the vast resources of the central government was unable to understand the specific local conditions, so that inefficient use of funds, on the one hand facing the local financial performance evaluation, on the other hand, transactions within the scope of the functions of the lack of necessary funds, so that the difference between them can not be balanced. In this situation rationalize the central and local fiscal relations are very necessary.

At present, China's basic education providers of public services and the equalization process actors are local governments below the provincial, regulate the financial relationship between central and local governments to better rural and urban basic education equalization of public services.

First, to come forward to build the minimum standards of basic education programs involving public service for specific projects by the central government, during what is the definition of basic education and the scope of the definition of public services is a clear points, and confirmed that a balanced foundation of basic education to meet the public service minimum standards on the calculation mode.

Second, to gradually standardize the province and the following specific responsibilities of local government expenditure in the division of functions to achieve a reasonable sharing mode, for example, the regional government is responsible for public services at the provincial level of basic education provided mainly related to the economic structure, environmental protection and agencies operate, in addition, the need is mainly responsible for social security and compulsory education expenditure, municipal governments can focus responsible for social security, administrative supervision and assist in public service compulsory education and health care.

Third, we should improve the supervision and management mechanism, to build on the lower levels of government and the same level of government supervision and accountability system for elementary education within the public service where the area to assess and audit oversight.

(B) Specification of financial transfer payment system

Current financial transfer payment, there are more disadvantages, including a tax refund based high proportion of transfer payments, in 2014, the central tax rebates and transfer payments to local governments totaled 4.536168 trillion yuan, accounting for $70.74 \%$ of central government spending. Transfer payments are mainly in central transfers to local governments, and provincial governments transfer payment system is not perfect. In response to these problems, one of the key sound financial system is necessary to regulate the system of transfer payments.

First, transfer payments to enhance fiscal adjustment of financial transfer payment. The return of central government spending includes local taxes, spending this level of local general transfer payments and the payment of the local projects. Such allocation based on the following, general transfer payments from the central through can make up for lack of local own revenue expenditure; special transfer payments by the central delegation to meet local public service affairs; commonality of public service in the supply process, making shared responsibility and balance, to adapt the division ratio, while income and expenditure to ensure a certain degree of equality.

Second, the financial transfer payment structure need to constantly upgrade and optimization. For example, increased merger and efforts to clean up the general transfer payments, transfer ratio 
and enhance its efficiency. Gradually increase the intensity of the public service for some remote areas and towns of transfer payments, encourage long-term counterparts in transfer payments between local and lateral balance.

(C) To break barriers to urban-rural dual financial structure

Equal city as a unit compared to fiscal, county financial difficulties for the public service to bring basic education funding shortage. To ease the financial difficulties of counties and townships, it is to break the fundamental urban-rural dual financial structure, to achieve urban and rural areas. Fiscal provincial and prefecture-level city is responsible for the financial division of responsibilities within the region, the burden of financial responsibility for urban and rural areas. Gradually increase the provincial fiscal transfer payment scale below. Break Binary fiscal system reform is not just financial, but also the distribution of the overall macroeconomic reform. The central government will keep abreast of the local financial situation, while fiscal revenue and expenditure for urban and rural areas have macroscopic, county and township financial difficulties that have arisen in the process of providing public services to be performed in a timely manner in order, to build the same level of direct control of the county financial model, clear estimates of expenditure in the financial district level, do real-time monitoring to ensure the normal operation of the county's finances, urban and rural basic education equalization of public services to provide an institutional guarantee.

(D) To promote basic education in urban and rural public service building

Construction of Basic Education Public Service System to continue to accelerate service-oriented government building, to change the ruling philosophy, namely to establish a "people-oriented" concept of governance, making public service delivery process to achieve control from the executive tube to humane treatment; to establish collaborative services idea, good coordination between government departments responsibilities, avoid overlapping responsibilities and vacancies; to achieve equalization of urban and rural public services, government must first have the idea of equalization.

First, build a sound evaluation system is a prerequisite. A good evaluation system and a sound system construction is any essential part, specific to the issue of equalization of this article, to build this system is the principle of basic education in the process of building the equalization of public services need to adhere to long-term, therefore, Governments need to constantly improve the performance evaluation system, while establishing a clear process for public service providers subject, object, program oversight in the evaluation system, the introduction of the necessary audit links to regulatory capital operation.

Second, improve the supply system is to protect the community autonomy. Start from the framework of the community to take the initiative themselves in public service supply system, in conjunction with the urban and rural management, the initiative to explore the grassroots community service management, to achieve self-build, own decisions. But also to fully listen to public opinion during the independent community services, all to the demands of the residents based. At the same time, community natural resource integration conditions and unique grassroots community facilities close to the people, by providing a comprehensive community public service facilities are very correct choice. Relative to the mature urban communities and rural areas there could be a large number of villages left behind, left behind can organize local village staff set up social care organizations, make full use of resources to develop public services in order to practice the pension, to help the young.

Finally, a comprehensive system security is the foundation. Basic education public service covers the basic demands of urban and rural residents of public goods, from basic elementary 
education to involve the national economy and health care, from social security to the infrastructure, related to the basic living of urban and rural residents. To this end, a sound basic education in the public service system needs to run an independent regulatory body, despite some difficulty in the operation, however, the urban and rural basic education in order to achieve the equalization of public services, it is necessary "equal justice", unity regulatory model in favor of a unified independent financial, centralized scheduling and investment in public services.

\section{REFERENCE:}

[1] Cai Fang. Government Functions Change to Provide Basic Public Services [J]. Economic Research, 201012.

[2] Fan Liming, Guo Jian. International Comparison of Urban and Rural Equalization of Basic Public Services, Processes and Experience [J]. Central University of Finance and Economics, 20127.

[3] Liu Chengkui, The Dynasty Was: Urban and Rural Basic Public Service Equalization Index System [J]. Financial Research, in 2011 The First Eight.

[4] Qi Yu: Equalization of Basic Public Services in Urban and Rural Situation and Policy Recommendations-Based on The Perspective of Government Preferences and Household Demand [J]. Local Financial Research, in 2010. 